\title{
Supercritical Fluids as a State-of-the-Art Formulation Method of Nanoparticles for Ocular Drug Delivery
}

\author{
By Naida Omerović \& Edina Vranić
}

University of Sarajevo

Abstract- Conventional ophthalmic dosage forms, although being simple to apply and presenting great patients' compliance, display poorer drug bioavailability and retention time on the eye surface. To cope with these problems, one must formulate novel drug delivery systems, such as nanosystems, for ocular drug delivery. Different formulation methods of nanoparticles have been developed, but some of them, such as the supercritical fluid method, have not reached their full potential in ocular drug delivery. This article aims to present the possibilities of the supercritical fluid method when preparing nanosystems for ocular drug delivery. This method could be used more frequently and efficiently because it is environmentally friendly and produces nanoparticles of the desired physicochemical properties, which is especially important in ocular drug delivery considering its peculiarities. Modifications of the supercritical fluid method can be used when a drug has some specific properties, which is an additional benefit in ocular drug delivery.

Keywords: nanosystems, nanoparticles, ocular drug delivery, supercritical fluids.

GJMR-B Classification: NLMC Code: QV 785

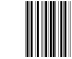

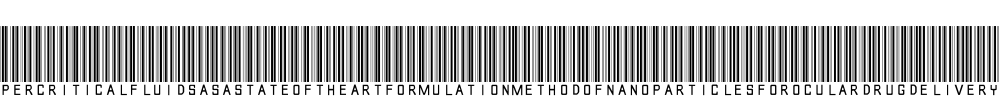

Strictly as per the compliance and regulations of:

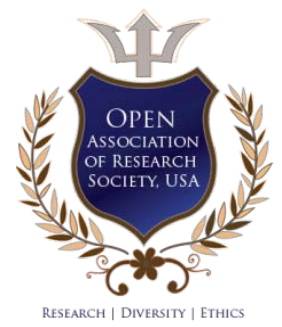

(C) 2021. Naida Omerović \& Edina Vranić. This research/review article is distributed under the terms of the AttributionNonCommercial-NoDerivatives 4.0 International (CC BY-NC-ND 4.0). You must give appropriate credit to authors and reference this article if parts of the article are reproduced in any manner. Applicable licensing terms are at https://creativecommons.org/licenses/by-nc-nd/4.0/ 


\title{
Supercritical Fluids as a State-of-the-Art Formulation Method of Nanoparticles for Ocular Drug Delivery
}

\author{
Supercritical Fluids in Nano-Ophthalmology
}

Naida Omerović ${ }^{\alpha} \&$ Edina Vranić ${ }^{\sigma}$

Abstract- Conventional ophthalmic dosage forms, although being simple to apply and presenting great patients' compliance, display poorer drug bioavailability and retention time on the eye surface. To cope with these problems, one must formulate novel drug delivery systems, such as nanosystems, for ocular drug delivery. Different formulation methods of nanoparticles have been developed, but some of them, such as the supercritical fluid method, have not reached their full potential in ocular drug delivery. This article aims to present the possibilities of the supercritical fluid method when preparing nanosystems for ocular drug delivery. This method could be used more frequently and efficiently because it is environmentally friendly and produces nanoparticles of the desired physicochemical properties, which is especially important in ocular drug delivery considering its peculiarities. Modifications of the supercritical fluid method can be used when a drug has some specific properties, which is an additional benefit in ocular drug delivery.
Keywords: nanosystems, nanoparticles, ocular drug delivery, supercritical fluids.

\section{INTRODUCTION}

( ifferent eye barriers present a challenge for drug delivery to the eye (Figure 1). These barriers are $[1,2]$ :

- Anatomical (conjunctiva, sclera, choroid, retina, with the blood-retinal barrier (BRB) comprising retinal capillary endothelial cells and retinal pigment epithelium (RPE)).

- Physiological (removal of the solution by blinking, dilution of the solution by tearing).

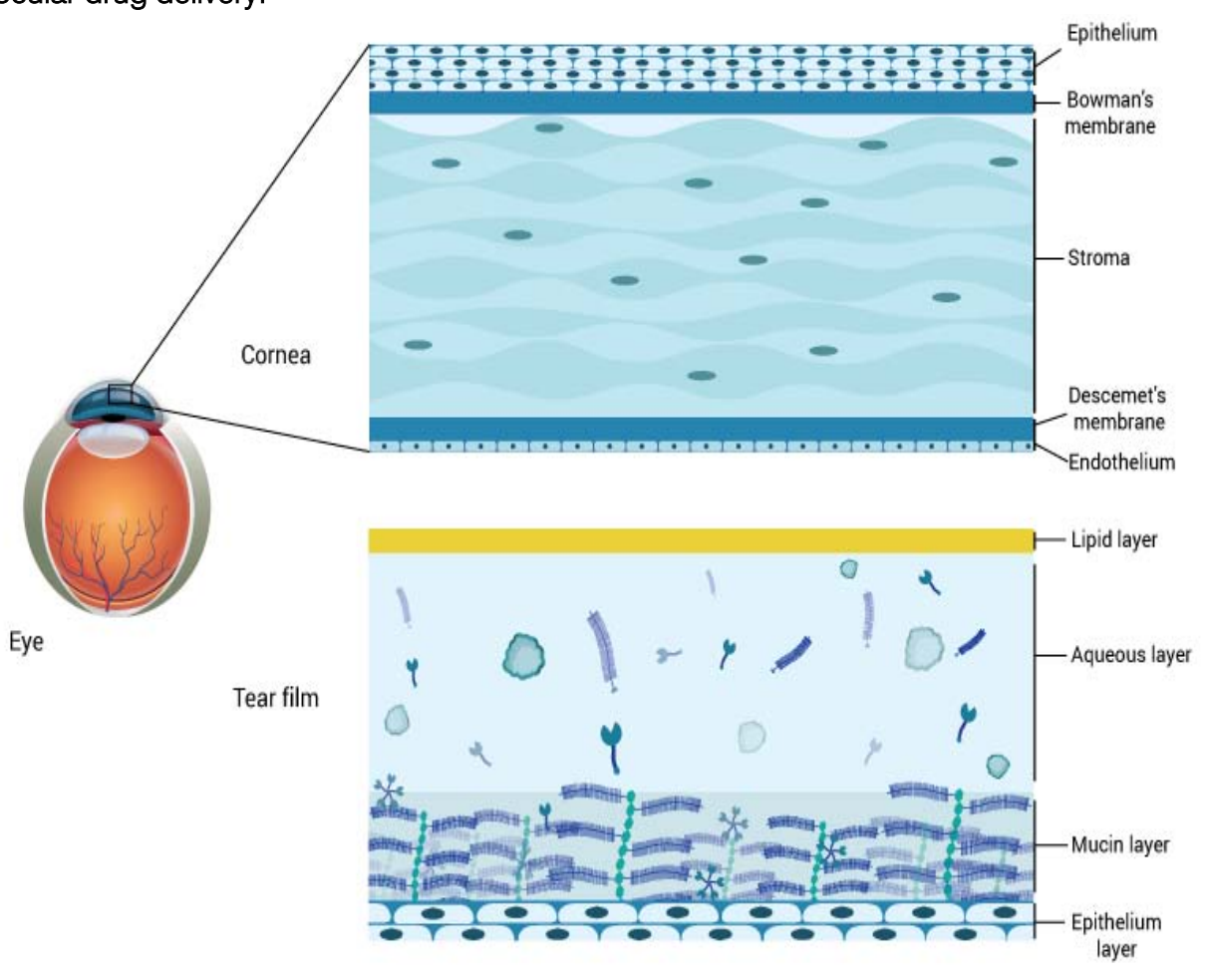

Figure 1: Different eye layers

Author a: Department of Clinical Pharmacy, Faculty of Pharmacy, University of Sarajevo, Zmaja od Bosne 8, 71 000 Sarajevo, Bosnia and Herzegovina.e-mail: naida.omerovic@ffsa.unsa.ba

Corresponding Author o: Department of Pharmaceutical Technology, Faculty of Pharmacy, University of Sarajevo, Zmaja od Bosne 8,71 o00 Sarajevo, Bosnia and Herzegovina. e-mail: edina.vranic@ffsa.unsa.ba 
They are an obstacle during the development of different ophthalmic dosage forms $[3,4]$. Conventional ophthalmic dosage forms include eye drops, ointments, suspensions, and emulsions. These formulations have proven their advantages, such as great patients' compliance and easy applicability, but their limitations include more frequent administration to get the therapeutic drug concentration, as well as poor drug bioavailability. Conventional ophthalmic dosage forms are more powerful in the treatment of the diseases of anterior rather than posterior eye segment. Previously mentioned dosage forms can also cause the occurrence of eye irritation, eye redness, and visual impairment $[5,6]$.
To cope with these disadvantages of conventional ophthalmic dosage forms, novel drug delivery systems for ocular drug delivery are being developed, wherein nanosystems get special attention. Nanosystems that can be used as ocular drug delivery systems include nanoparticles, nanomicelles, liposomes, niosomes, dendrimers, nanosuspensions, nanoemulsions, nanocrystals, etc (Figure 2). Their advantages are $[7,8]$ :

- Higher: drug permeability, bioavailability, and retention on the eye surface

- Lower: drug degradation, risk of visual impairment, required drug doses, and occurrence of side effects.

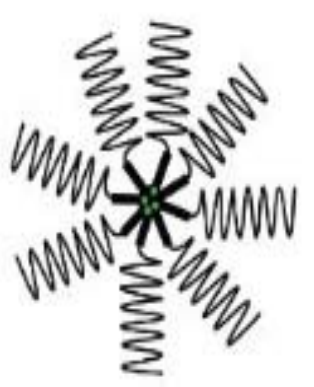

Nanomicelle

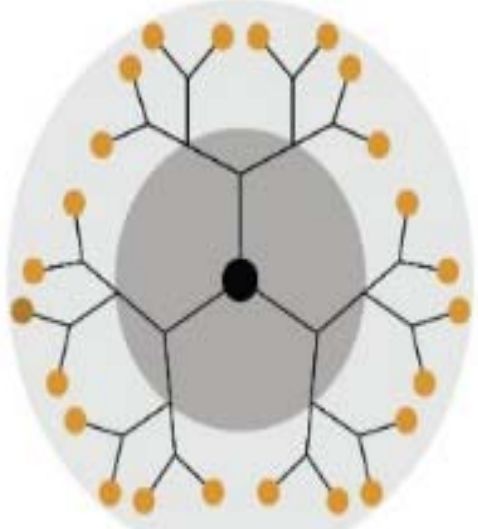

Dendrimer
Liposome

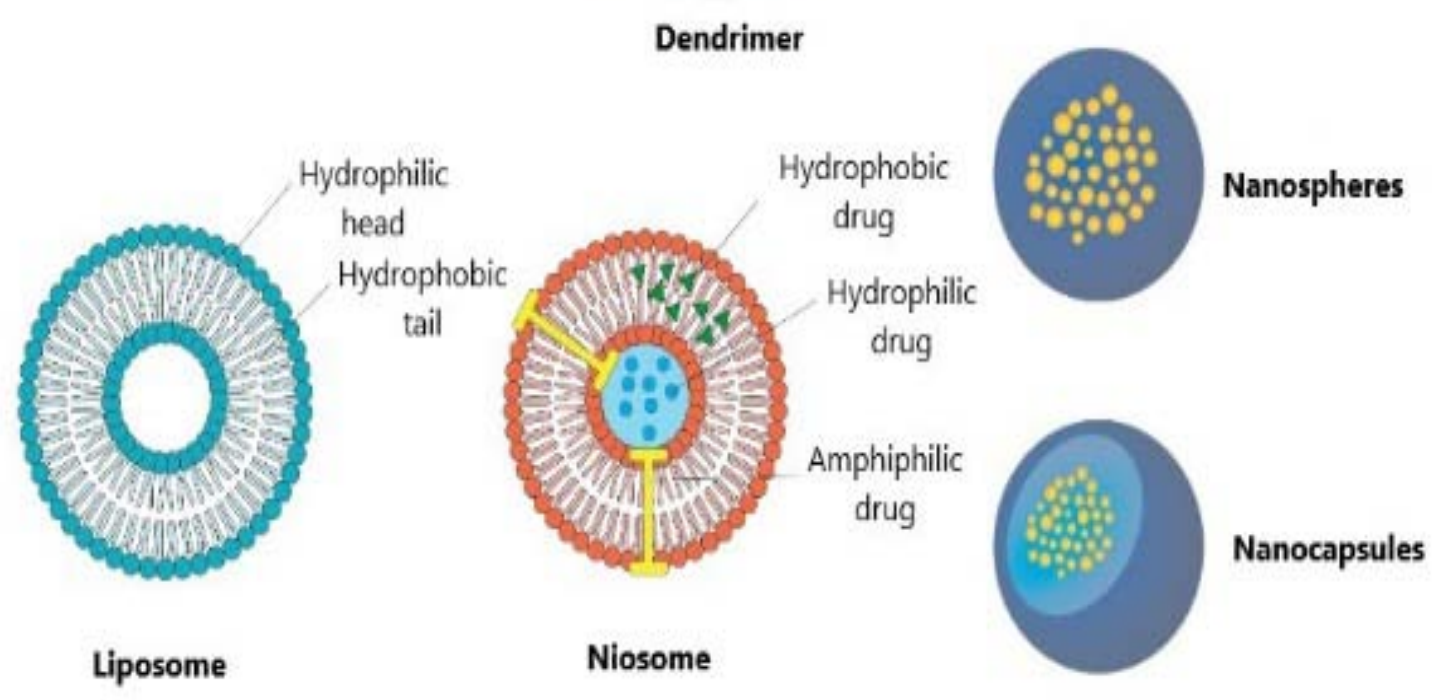

tail

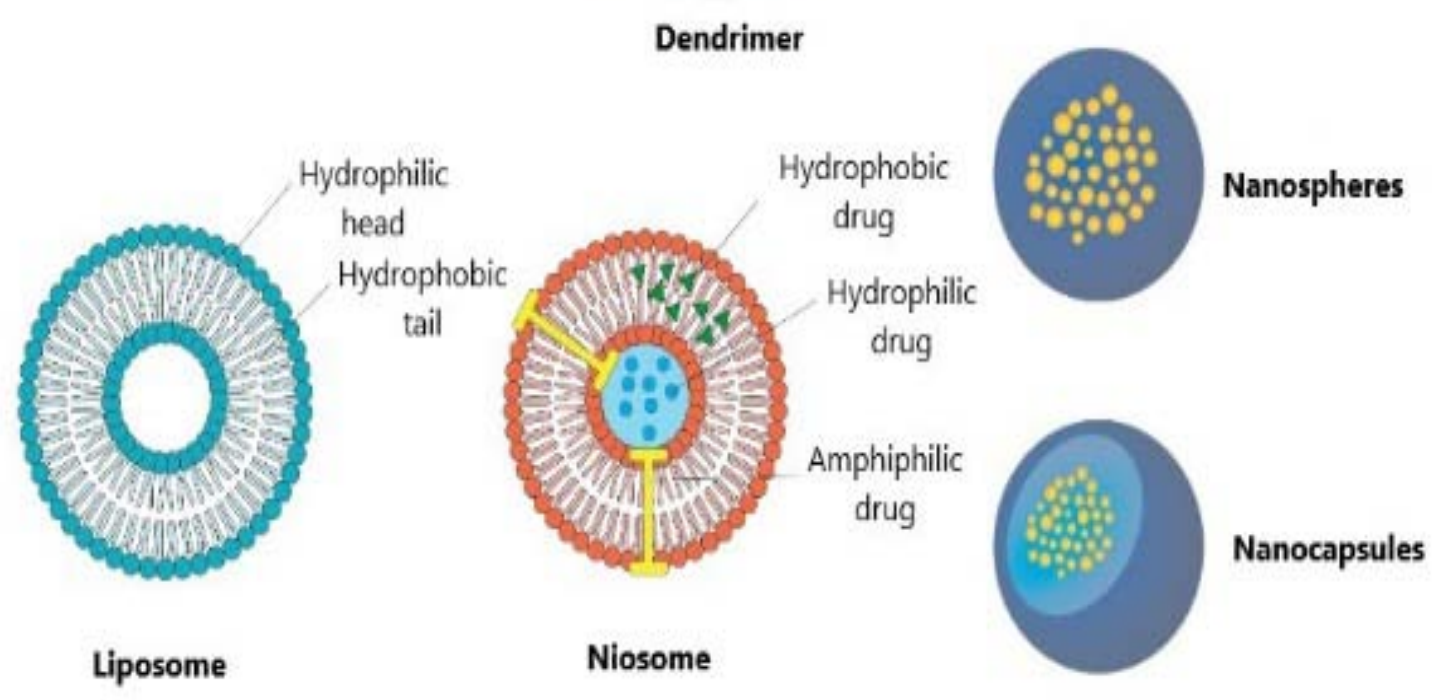

Niosome

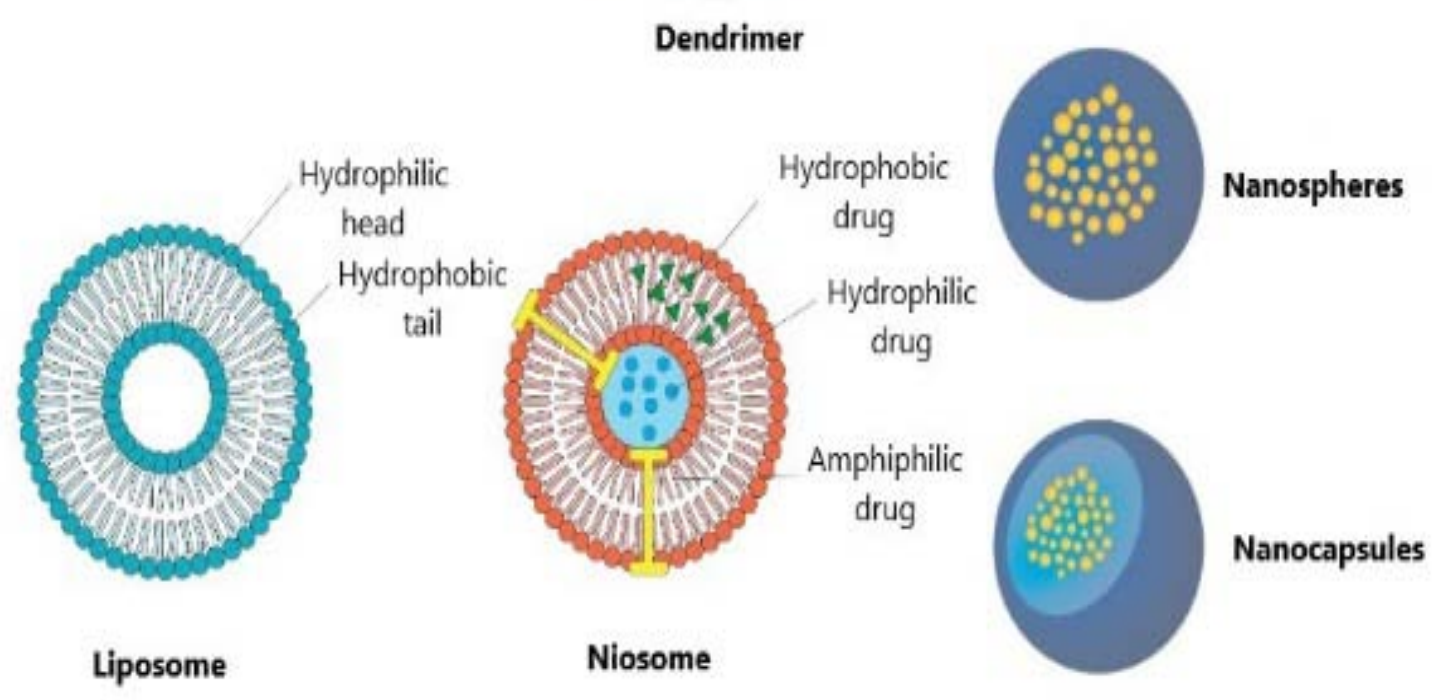

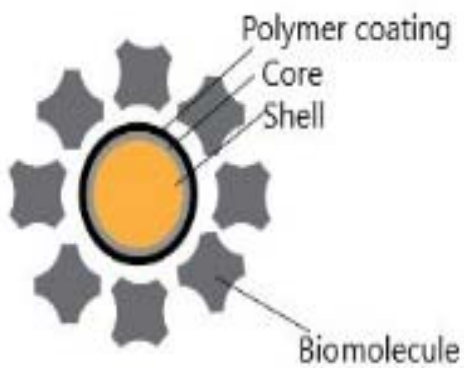

Nanocrystal

Figure 2: Types of nanosystems

There are two classifications of nanoparticles, the first being nanospheres and nanocapsules, and the second being polymeric nanoparticles and lipid nanoparticles. Nanospheres are matrix systems, in which a drug is adsorbed on the surface or evenly dispersed in the matrix. They have a solid core with a dense polymer around it, with a size from 100 to 1000 $\mathrm{nm}$. Nanocapsules are vesicular systems, in which a drug is usually dissolved in the particle's nucleus, but it can also be adsorbed on the surface. They have an oilfilled cavity with a firm polymeric envelope around it, with a size from 10 to $1000 \mathrm{~nm}[9,10]$. In polymeric nanoparticles, a drug is dissolved or encapsulated in different polymers. These nanoparticles have a size from 
10 to $100 \mathrm{~nm}$, are biodegradable, non-toxic, biocompatible, and mucoadhesive. Polymers can be made either by the direct process of polymerisation of different monomers or from derived polymers [11]. Lipid nanoparticles comprise lipids that are solid at room and body temperature, unlike water/oil (w/o) emulsions that have liquid lipids. These nanoparticles have a size from 150 to $300 \mathrm{~nm}$, are non-toxic and long-term stable, protect a drug from its degradation, present controlled drug release and improved drug bioavailability. There are two groups of lipid nanoparticles: solid lipid nanoparticles (SLN) and nanostructured lipid carriers (NLC) [12]. The SLN comprise a solid lipid with an incorporated drug, and water, co-emulsifiers, and emulsifiers as excipients [13]. The NLC incorporate liquid and solid lipids as the basic matrix [14].

Factors that must be considered when designing an ocular drug delivery nanosystem are [15]:

- $\quad$ Size of nanoparticles

- Blood and lymphatic circulations

- Melanin pigmentation

- Diseases

- Functionalization of nanoparticles

- Charge of nanoparticles.

These factors are discussed in the following paragraphs.

Amrite et al. conducted a study to determine the distribution of carboxylate-modified, negatively charged polystyrene (PS) nanoparticles in the eye. Nanoparticles, sizes of $20 \mathrm{~nm}$ and $200 \mathrm{~nm}$, were applied subconjunctivally to Sprague Dawley rats. Nanoparticles of $200 \mathrm{~nm}$ were detected two months post-application in the periocular tissue of the eye, whereas nanoparticles of $20 \mathrm{~nm}$ were not, as they were fastly eliminated from that tissue. Subconjunctivally applied nanoparticles of $200 \mathrm{~nm}$ and larger could be kept at the site of application for at least two months, which meant that nanosystems of this size could be useful as controlled drug delivery nanosystems for periocular application [16]. Amrite et al. conducted another study to investigate the transscleral permeability of celecoxibloaded nanoparticles, sizes of $20 \mathrm{~nm}$ and $200 \mathrm{~nm}$, in the presence and absence of blood and lymphatic circulations in Sprague Dawley rats. Various clearance rates showed that the clearance of nanoparticles affected the concentrations of celecoxib in the retina. Larger nanoparticles showed sustained drug delivery in the retina better compared with the smaller ones, but these differences were reduced with an increase in the release rate of celecoxib from nanoparticles. Blood and lymphatic circulations played an important role in the clearance of the $20 \mathrm{~nm}$-sized nanoparticles, which were transported across the sclera in a minimal amount, but with significant transport across the sclera-choroid-RPE, because of their fast disposition in the presence of blood and lymphatic circulations. The $200 \mathrm{~nm}$-sized nanoparticles displayed low clearance by blood and lymphatic circulations and were suitable for controlled transscleral drug delivery [17].

Cheruvu et al. conducted a study to determine the effect of the melanin pigmentation on the transscleral delivery of celecoxib-loaded nanoparticles in Sprague Dawley (non-pigmented, albino) and Brown Norway (pigmented) rats. The affinity and the extent of the binding of celecoxib to natural melanin were not significantly different compared with those to synthetic melanin. Transscleral retinal and vitreal drug deliveries of celecoxib were significantly lower in Brown Norway rats compared with those in Sprague Dawley rats, which could be attributed to the significant binding of celecoxib to melanin and its accumulationin the melanin-rich choroid-RPE [18]. Cheruvu et al. conducted another study to investigate the effect of diabetes on the transscleral delivery of celecoxib-loaded nanoparticles in Sprague Dawley and Brown Norway rats. Transscleral retinal and vitreal drug deliveries were significantly higher in diabetic animals of both Sprague Dawley and Brown Norway rats, which could be attributed to the disruption of the BRB because of diabetes. Transscleral delivery of celecoxib was higher in Brown Norway rats compared with that in Sprague Dawley rats [19].

Kompella et al. conducted a study to determine whether topical ocular drug delivery of nanoparticles of size $<100 \mathrm{~nm}$ could be enhanced by their coating with peptides or proteins in the bovine eye. The uptake of nanoparticles was in the following order: corneal epithelium $>$ stroma $>$ endothelium, with concentrations in the aqueous humour being undetectable. Transport across the cornea was enhanced because of the functionalization of PS nanoparticles of $20 \mathrm{~nm}$ with deslorelin, a luteinizing hormone-releasing hormone $(\mathrm{LHRH})$ agonist, as well as transferrin. Surface modification of nanoparticles by conjugating a LHRH agonist or transferrin was useful to provide fast and efficient delivery of nanoparticles across the cornea [20]. Eljarrat-Binstock et al. conducted a study to determine the penetration of positively and negatively charged fluorescent nanoparticles in rabbits. Positively charged nanoparticles showed better penetration into the inner ocular tissues compared with the negatively charged ones [21]. Kim et al. conducted a study to investigate the movement of intravitreally applied human serum albumin (HSA) nanoparticles concerning the surface charge of nanoparticles. Either cationic or anionic HSA nanoparticles were injected to determine the effect of surface charge on the intravitreal movement of nanoparticles. Anionic nanoparticles with a surface charge of $-33.3 \pm 6.1 \mathrm{mV}$ diffused more easily through the collagen fibres compared with the cationic ones with a surface charge of $11.7 \pm 7.2 \mathrm{mV}$. Anionic HSA nanoparticles presented a promising drug delivery nanosystem to the subretinal ocular tissue and RPE 
[22]. Cationic polymers highly interact with the negatively charged hyaluronan in the vitreous cavity of the eye. The PS nanoparticles showed an interaction with collagen fibres in the sclera, which resulted in their poor diffusion through the vitreous cavity. Many modifications have been developed to cope with the effect of the above-mentioned factors, such as [23]:

- Surface modification of nanoparticles with poly(ethylene glycol) (PEG), also known as PEGylation

- Masking the reactive surface of nanoparticles

- Targeting the specific transporters or receptors on the cell surface.

Having in mind all these specificities of ocular drug delivery, as well as the fact that newer formulation methods of nanoparticles, such as the supercritical fluid method, have not been used in preparing ocular drug delivery nanosystems so much, this article aims to present the possibilities of the use of the supercritical fluid method when preparing nanosystems for ocular drug delivery.

\section{il. Formulation Methods of Nanoparticles For OCULAR DRUG Delivery: Classification and Steps}

The most important methods of formulating the nanoparticles that are used in ocular drug delivery can be classified as [24,25]:

- Polymerisation of a monomer:

o Emulsion polymerisation

o Interfacial polymerisation

o Interfacial polycondensation

- Production from pre-formed polymers:

o Solvent removal

o Interfacial deposition

o Emulsification - solvent evaporation

o Emulsification - solvent diffusion

o Salting-out

- Production from natural macromolecules:

o lonic gelation

- Desolvation of macromolecules

- Newer methods: supercritical fluid

- Other methods: homogenisation and milling.

a) Supercritical fluid

A supercritical fluid is a substance under a condition above its critical points, which are the highest temperature and pressure at which a substance exists as the gas and the liquid in equilibrium. Thus, a supercritical fluid shows the properties of both gases (such as penetration) and liquids (such as dissolution) simultaneously. Gases, such as carbon dioxide $\left(\mathrm{CO}_{2}\right)$, ammonia $\left(\mathrm{NH}_{3}\right)$, or water $\left(\mathrm{H}_{2} \mathrm{O}\right)$, can be converted to supercritical fluids under particular conditions. But only supercritical $\mathrm{CO}_{2}$ can be economically useful because its critical points (temperature $=31.1^{\circ} \mathrm{C}$, pressure $=$ 73.8 bar) are relatively easy to reach [26].

Supercritical fluids have great potential in the production of nanosystems but have not been used frequently in ocular drug delivery. Studies conducted so far include the preparation of dexamethasone [27] and griseofulvin [28] nanoparticles. This method can replace the use of organic solvents while preparing nanoparticles for advanced drug delivery and formulation systems, such as the ocular ones. What makes a difference between conventional formulation methods, such as freeze- or spray-drying, where larger particles are primarily formed and then reduced to the desired size, is the fact that the supercritical fluid method instantly forms particles in a manner to get the desired properties. This is the way to avoid the unwanted effects caused by the energy transfer in the system, which is needed to reduce the size of particles. Particles formed this way do not have to undergo additional treatment, which is a significant advantage $[29,30]$.

The most important characteristic of this method is the fact that there is no phase boundary between the gas and the liquid, so there is continuity in the physicochemical properties of the fluid. With small variations in pressure and temperature of the system, the properties of supercritical fluids are alterable from the gas to the liquid, therefore the viscosity and diffusivity are closer to those of the gas and the density is closer to that of the liquid [31].

The most important types of the supercritical fluid method include [24,32]:

- Supercritical anti-solvent (SAS)

- Rapid expansion of the supercritical solution (RESS).

\section{i. Supercritical anti-solvent (SAS)}

The SAS method includes the precipitation of a solute in a compressed fluid under supercritical conditions. The precipitation can be done in two ways [33]:

1. An anti-solvent can be added to a solution (normaladdition precipitation)

2. A solution can be added to an anti-solvent (reverseaddition precipitation).

A supercritical anti-solvent must be miscible with a solution solvent, whereas a solute must not be soluble in a supercritical anti-solvent [33].

In normal-addition precipitation, first, a solute is dissolved in a liquid solvent, and second, a supercritical anti-solvent is added to a solution. The latter is done in a partially filled container at the ambient pressure. With the addition of a supercritical anti-solvent, both the pressure of a closed container and the volume of a solution/antisolvent mixture increase. With an increase in the anti- 
solvent fraction in the mixture and a decrease in solubility of a solute, the precipitation of a solute occurs. To get nanoparticles of the desired physicochemical properties, the precipitate is washed with an anti-solvent [33].

In reverse-addition precipitation, first, a liquid solution is sprayed into a supercritical anti-solvent. The precipitation of a solute occurs because of the fast diffusion of a solvent from the solution sprayed into a supercritical anti-solvent. Second, the precipitate is washed with an anti-solvent and filtered to get nanoparticles of the desired physicochemical properties [33].

No matter whether the precipitation of a solute is normal or reverse, both the size and size distribution of nanoparticles depend on [33]:

- The selection of a solution/anti-solvent mixture
- The concentration of a solute

- The relative quantities of a solution and an antisolvent

- The rate of the anti-solvent addition

- The degree of mixing.

In a study conducted by Subramaniam et al., the size of nanoparticles depended on the pressure because smaller nanoparticles are formed when the pressure of an added anti-solvent increases. This was attributed to the faster nucleation of a solute [34]. In a study conducted by Rantakylä et al., the size of nanoparticles depended on both temperature and pressure, but was independent of the nozzle exit velocity and diameter. The initial size of droplets did not affect the size of nanoparticles [35].

The SAS method is presented in Figure 3.

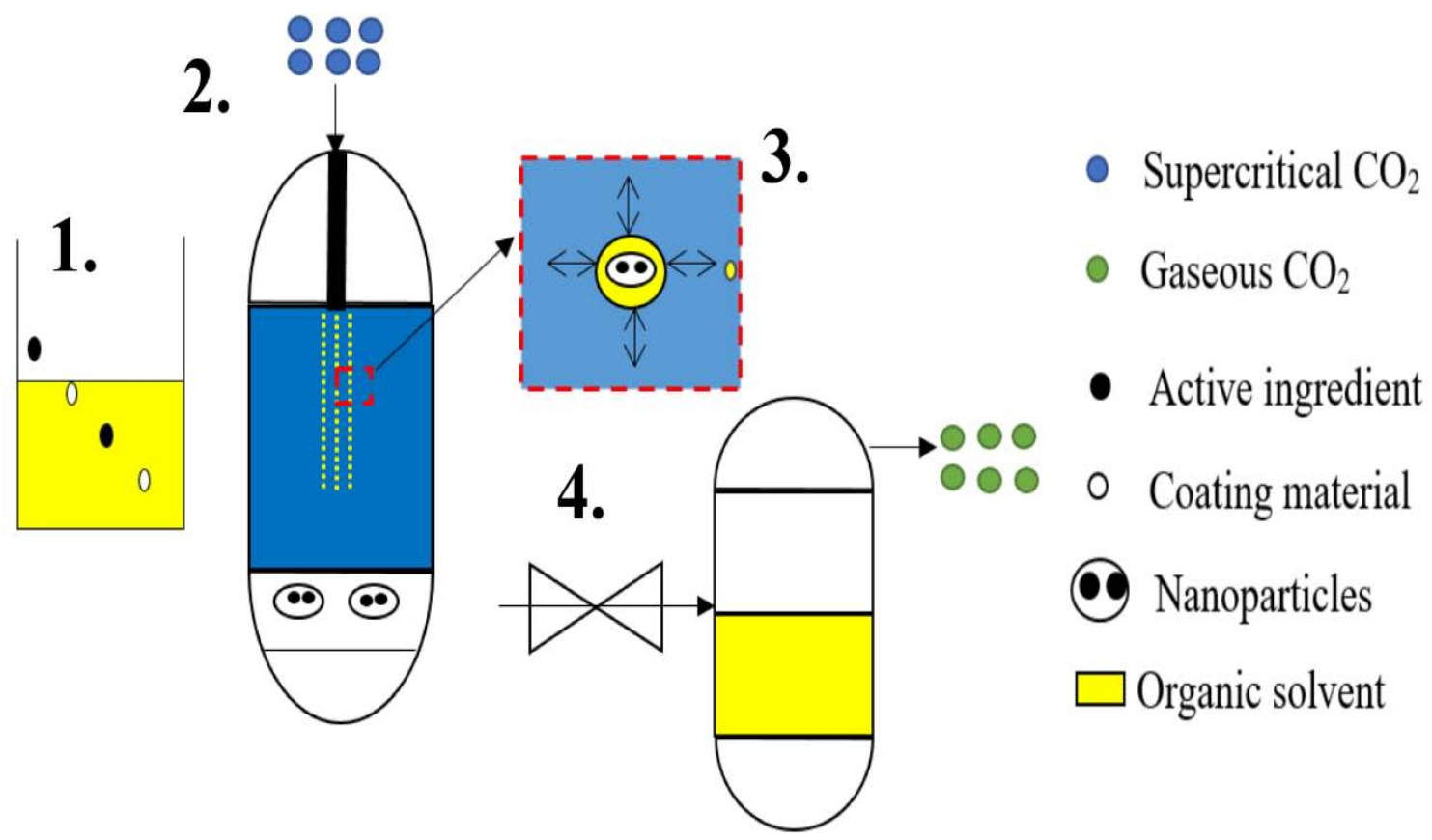

Figure 3: The supercritical anti-solvent (SAS) method

1. An active ingredient and a coating material are dissolved in an organic solvent.

2. The organic solution is sprayed into supercritical $\mathrm{CO}_{2}$.

3. Supercritical $\mathrm{CO}_{2}$, as an anti-solvent, leads to supersaturation and precipitation of nanoparticles.

4. When the expansion occurs, $\mathrm{CO}_{2}$ reverts to its gaseous state, while an organic solvent is being removed.

One advantage of the SAS method is the fact that supercritical fluids are environmentally safe, thus this method could be used for preparing biodegradable nanoparticles, which is recommended in ocular drug delivery. Nevertheless, there are some new modifications of this method, which include the nebulisation of a solution by supercritical fluids that also behave as anti-solvents to precipitate a solute. Here, a solution and a supercritical fluid are mixed and sprayed into a drying atmosphere. Examples are [36-39]:

- $\mathrm{CO}_{2}$-assisted nebulisation with a bubble dryer (CAN-BD)

- Supercritical fluid-assisted atomisation (SAA).

A big disadvantage of the SAS method is the fact that the formation of nanoparticles is followed by a long drying period, which can lead to their agglomeration and aggregation. Still, this problem is manageable by intensive mixing of a solution with a supercritical anti-solvent. This can lead to a more efficient and enhanced mass transfer caused by the sonic waves in an energising gas stream, as well as the smaller size of droplets, by using an ultrasonic nozzle. The preparation of nanoparticles at low temperature is 
important for drugs that are thermally labile or shocksensitive, such as some drugs used in the treatment of ocular diseases. Still, many substances have a higher solubility in liquid solvents compared with lowtemperature supercritical fluids, and the SAS method allows a higher flow rate [40].

\section{ii. Rapid expansion of the supercritical solution (RESS)}

The RESS method differs from the SAS method because, in the RESS method, first, a solute is dissolved in a supercritical fluid to form a solution, and second, a solution is quickly expanded into an area of lower pressure or ambient air [41-43]. A rapid decrease in pressure and density causes the precipitation of a solute. A supercritical solution can be generated in two ways, by [44]:

- Heating and pressurizing a solution at room temperature (expansion is performed at a constant concentration)

- Continuously extracting a solute with an extraction column (useful for solutes insoluble in solvents).

The temperature of a solvent can differ from or be the same as the temperature at which the rapid expansion is performed. Both the extraction temperature and flow rate control the concentration of a solute. Rapid expansion from supercritical to ambient pressure leads to supersaturation because the solubility of supercritical fluids can be over 100 times higher compared with that under ideal gas conditions. Fast reduction of pressure results in the homogeneous nucleation of a solute but narrow size distribution of nanoparticles [44].

The RASS method can be used for preparing organic, inorganic, or polymeric nanomaterials. Fibres of polymeric nanomaterials can be prepared under the controlled expansion conditions, therefore variations in these conditions allow modifications of physicochemical properties of nanoparticles. Pre-expansion temperatures that are significantly higher or lower compared with the melting point of a polymer are used to create particles, whereas those that are close to the melting point of a polymer are used to create fibres [44].

The RASS method could also create nanoparticles with the controlled release of drugs, which could be very useful in ocular drug delivery [29]. The physicochemical properties of nanoparticles depend on various processing conditions, which allow control over them. Microparticles are generally obtained as primary products, but nanoparticles $(100-300 \mathrm{~nm})$ can also be produced in the RESS method by using the appropriate nozzles [45].

The RESS method requires minimum to no organic solvent. The precipitation process is enhanced because of the decrease in pressure and temperature that a solute goes through during the rapid expansion [46]. Caution should be taken regarding the occurrence of agglomeration and aggregation during the rapid expansion $[47,48]$.

A big disadvantage of the RESS method with supercritical $\mathrm{CO}_{2}$ is the low solubility of polar drugs. This method only applies to solutes that show good solubility in supercritical $\mathrm{CO}_{2}$. Poorly soluble substances with high molecular weights and polar bonds are great candidates for preparing nanoparticles, but many of them have low to negligible solubility in supercritical $\mathrm{CO}_{2}$ at temperatures less than $60{ }^{\circ} \mathrm{C}$ and pressures less than 300 bar. Co-solvents could be added to $\mathrm{CO}_{2}$ to enhance drug solubility [46]. To cope with this problem, a modified method of RESS with solid co-solvent (RESSSC) was proposed. A solid co-solvent provides an obstacle for coagulation, enhances the solubility, and can be later removed by lyophilisation (sublimation) [4951]. Rapid expansion from supercritical to aqueous solution (RESAS) is another modification, which produces nanoparticles of water-insoluble drugs [5254].

The RESS method is presented in Figure 4. 


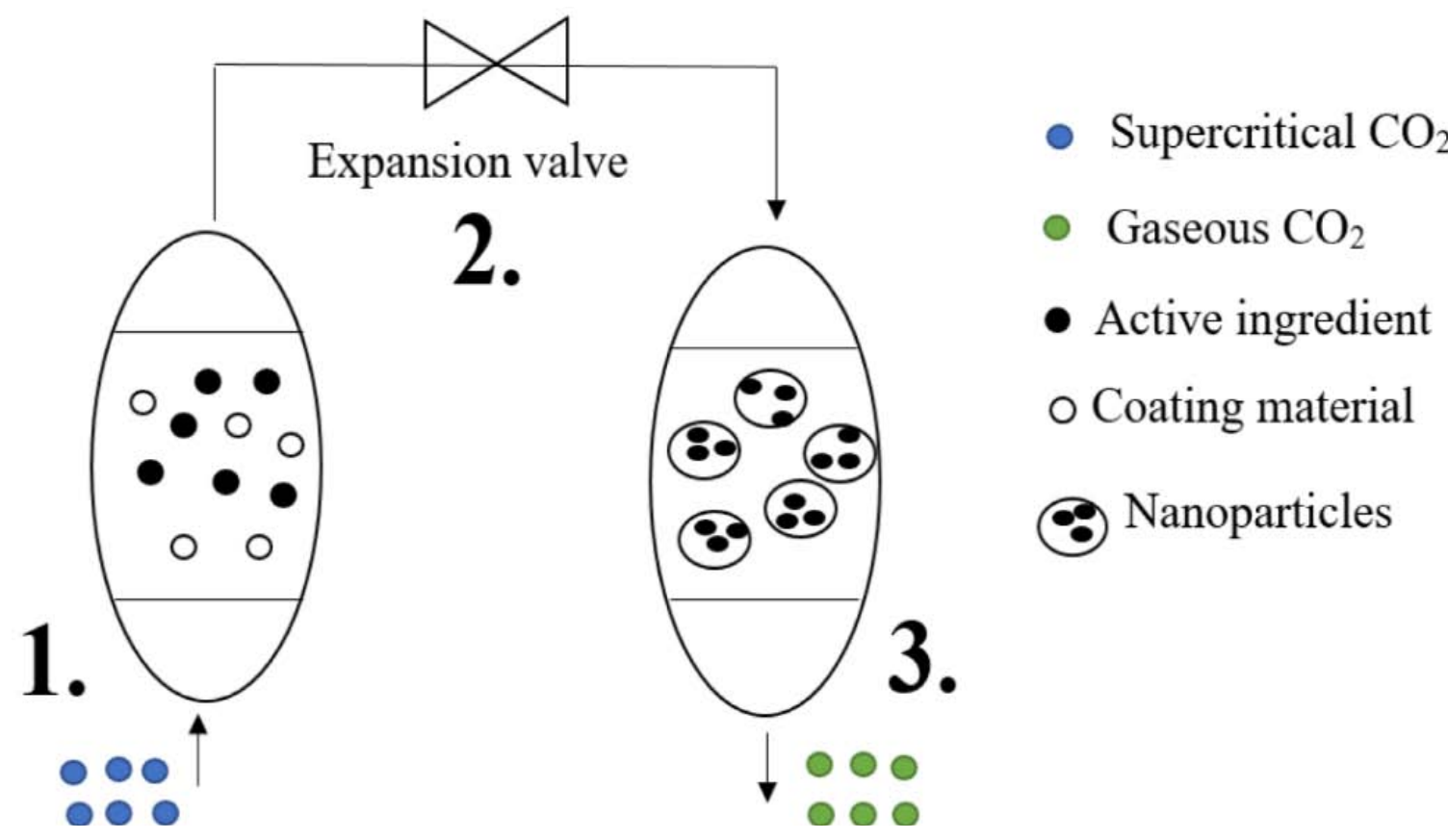

Figure 4: The rapid expansion of the supercritical solution (RESS)

1. An active ingredient and a coating material are dissolved in supercritical $\mathrm{CO}_{2}$.

2. When the expansion occurs, $\mathrm{CO}_{2}$ reverts to its gaseous state.

3. Nanoparticles are formed because of the decrease in solubility and precipitation of an active ingredient and a coating material.

iii. Operating parameters affecting the properties of nanoparticles formed by the supercritical fluid method

Various thermodynamic and aerodynamic factors, as well as properties of the material, affect the morphology, shape, size, and size distribution of nanoparticles. Thermodynamic factors include temperature, pressure, rate of addition of substances, as well as phase and composition changes during the expansion. Aerodynamic factors include nozzle geometry, mechanical shear, and impact distance of the jet against a surface [46].

Table 1: Studies conducted regarding the operating parameters affecting the properties of nanoparticles formed by the supercritical fluid method

\begin{tabular}{l|l}
\multicolumn{1}{c}{ the supercritical fluid method } \\
\hline STUDY & \multicolumn{1}{c}{ REMARKS } \\
\hline [55] & $\begin{array}{l}\text { Mathematical modelling of particle growth and nucleation during the supercritical fluid method was presented. } \\
\text { The flow rate was steady and one-dimensional. Partial expansion of supercritical solutions was proven to be an } \\
\text { effective way to form powders of desired size and other properties. The size of particles responded to the } \\
\text { extraction temperature (the temperature at which a solute is dissolved in a supercritical fluid), as well as the pre- } \\
\text { expansion temperature (the temperature at which the saturated mixture is isobarically pre-heated before the } \\
\text { expansion). A decrease in solubility upon isobaric heating embodied three trends predicted by calculations: an } \\
\text { increase in the size of particles upon the increase in pre-expansion temperature and a decrease in the size of } \\
\text { particles upon the increase in extraction temperature and pressure. }\end{array}$ \\
\hline$[56]$ & $\begin{array}{l}\text { Hydrodynamic modelling of the RESS method was presented. The expansion occurred at the nozzle inlet, along } \\
\text { with the nozzle, and in the expansion chamber, and the thermodynamic transformations for each step were } \\
\text { calculated, along with the temperature and pressure profiles. Flow rate at the nozzle exit was measured for two } \\
\text { supercritical fluids, } \mathrm{CO}_{2} \text { and fluoroform }\left(\mathrm{CHF}_{3}\right), \text { at different pre-expansion temperatures and pressures. } \\
\text { Computed values were comparable with the experimental data. }\end{array}$ \\
\hline
\end{tabular}

The supercritical fluid method allows the production of tiny particles (such as nanoparticles) and experiments conducted so far have shown that the size of particles, as well as some other properties, depend on a solvent, a solute, and the pre-expansion conditions. Still, there are some dilemmas regarding the relationship between the conditions of the process and the mechanism of the formation of particles. The interaction between nucleation, condensation, and coagulation is also important to understand. Thus, there is a need to model the supercritical fluid method and its conditions to better understand how different operating parameters affect the properties of the final product, such as nanoparticles. Some of the most cited studies conducted regarding the operating parameters affecting the properties of nanoparticles formed by the supercritical fluid method are presented in Table 1 , along with their most important remarks. 


\begin{tabular}{|c|c|}
\hline [57] & $\begin{array}{l}\text { A one-dimensional flow modelling of the RESS method was presented. The emphasis was on the wall friction in } \\
\text { the nozzle and heat interchange with the surrounding region. Calculations were performed on the ibuprofen- } \\
\text { supercritical } \mathrm{CO}_{2} \text { system and supersaturation, as well as nucleation, were considered. Results showed that very } \\
\text { high supersaturation and nucleation rates can be obtained when the fluid leaves the nozzle exit. A decrease in } \\
\text { the size of particles was also visible. Sensitivity analyses showed that pre-expansion temperatures and } \\
\text { pressures, as well as the nozzle length, did not significantly influence the flow rate. }\end{array}$ \\
\hline [58] & $\begin{array}{l}\text { Modelling of the thermodynamic behaviour of supercritical solutions during the RESS method was presented } \\
\text { and an impact of the solubility and surface tension of different solutes in supercritical fluids on nucleation rates } \\
\text { under typical RESS conditions was investigated. Calculations showed that the nucleation rate is a solubility and } \\
\text { surface tension function. It was shown that it is not possible to investigate coagulation and homogeneous } \\
\text { nucleation separately. Also, the information about the properties of a solute needs to be more reliable. }\end{array}$ \\
\hline [59] & $\begin{array}{l}\text { Experiments were carried out with } \mathrm{CO}_{2} \text { and } \mathrm{CHF}_{3} \text { as supercritical fluids, as well as with cholesterol, benzoic acid, } \\
\text { and griseofulvin. It was shown that it is possible to produce particles of the desired size, which leads to improved } \\
\text { dissolution. Flow rate and the formation and growth of particles during the RESS method were modelled } \\
\text { numerically. The flow rate was steady and one-dimensional. Results showed that the formation of particles } \\
\text { mainly occurs in the supersonic free jet and that the primary mechanism of particle growth is coagulation. }\end{array}$ \\
\hline [60] & $\begin{array}{l}\text { The size distribution of fine powders formed during the RESS method depends on the operating parameters and } \\
\text { the geometry of the expansion utensil. Homogeneous nucleation, condensation, and coagulation during the } \\
\text { expansion of a non-volatile solute in a supercritical fluid were modelled. Calculations showed that the RESS } \\
\text { method is very successful in the formation of particles in the diameter range of } 10-50 \text { nm. Delayed nucleation, } \\
\text { precipitation of a small solute fraction, and narrow size distribution of particles were mostly displayed. }\end{array}$ \\
\hline [61] & $\begin{array}{l}\text { In this study, it was shown that the aerodynamic factors remain constant over a wide range of pressures. The } \\
\text { formation of particles was probably a result of gas-phase nucleation and growth within the expansion utensil, } \\
\text { rather than within discrete liquid droplets. }\end{array}$ \\
\hline [62] & $\begin{array}{l}\text { In this study with the toluene (solvent)- } \mathrm{CO}_{2} \text { (anti-solvent) system, it was displayed that the size of droplets } \\
\text { depends on densities of both solvent and anti-solvent. It is recommended to work in a single-phase zone at high } \\
\text { pressure because higher mass transfer and supersaturation ratio are then achieved. Mathematical modelling of } \\
\text { mass transfer between an organic solvent and an anti-solvent was presented when two phases were miscible. } \\
\text { The mass transfer behaviour of droplets could affect the morphology of particles. Under supercritical conditions } \\
\text { of the mixture, a solvent and an anti-solvent were miscible. Thus, the interface between the droplets and their } \\
\text { environment was not defined. By defining a radius of droplets based on the difference in density between a } \\
\text { solvent and an anti-solvent, the mass transfer can be calculated, as well as an impact of the operating } \\
\text { parameters. Calculations showed droplets swell when a solvent has a higher density compared with an anti- } \\
\text { solvent, and shrink when an anti-solvent has a higher density compared with a solvent. Near the critical points of } \\
\text { the mixture, droplets swelled and were more sensitive to changes in temperature and pressure. The lifetime of } \\
\text { droplets was significantly shorter under miscible conditions. When the critical points of the mixture are close, } \\
\text { droplets swelled less. The extent of droplet swelling or shrinking was a temperature and pressure function } \\
\text { correlated to the difference in density and diffusivity between a solvent and an anti-solvent. Supercritical } \\
\text { conditions resulted in faster mass transfer, causing higher supersaturation and nucleation rates but the smaller } \\
\text { size of particles. }\end{array}$ \\
\hline$[63,64]$ & $\begin{array}{l}\text { The authors of these two studies investigated whether the spherical shape of particles results from the drying of } \\
\text { droplets after the atomisation of a liquid solution. Above the critical pressure, the surface tension influences the } \\
\text { formation of particles. When atomisation is not obtained, the precipitation from the fluid phase produces } \\
\text { particles. They also investigated the relationship between the solute concentration, the vessel temperature and } \\
\text { pressure, as well as the fraction of } \mathrm{CO}_{2} \text {. They concluded that the fraction of } \mathrm{CO}_{2} \text { greater than } 0.95-0.97 \text { is the } \\
\text { most useful for the formation of smaller particles. Critical points of the mixture of } \mathrm{CO}_{2} \text { and a liquid organic solvent } \\
\text { were then achieved. }\end{array}$ \\
\hline
\end{tabular}

\section{ili. Conclusion}

Novel drug delivery systems are continuously being developed for ocular drug delivery because of their many advantages compared with conventional ophthalmic dosage forms. Nanoparticles have especially been receiving attention. The most important formulation methods of nanoparticles for ocular drug delivery include polymerisation of a monomer (emulsion polymerisation, interfacial polymerisation, interfacial polycondensation), production from pre-formed polymers (solvent removal, interfacial deposition, emulsification - solvent evaporation, emulsification - solvent diffusion, salting-out), production from natural macromolecules (ionic gelation), desolvation of macromolecules, newer formulation methods (supercritical fluid), and other formulation methods (homogenisation, milling). The choice of the formulation method depends on an active pharmaceutical ingredient and other substances used, as well as the desired physicochemical properties of nanoparticles. New formulation methods are constantly being developed to get the most out of nanotechnology, such as the supercritical fluid method. The SAS method uses a liquid solvent and a supercritical fluid, which are miscible with each other, but a solute is not soluble in a 
supercritical fluid. Instantaneous precipitation of a solute, which is formed because of the extraction of a liquid solvent by a supercritical fluid, causes the formation of nanoparticles. In the RESS method, a supercritical fluid dissolves a solute. Consequently, the solvent power of a supercritical fluid is reduced and a solute precipitates because of its rapid expansion into an area of lower pressure. These methods can create nanoparticles of adequate size, size distribution, and other properties for ocular drug delivery, and should be applied more regularly.

Conflict of interest

The authors declare that there was no conflict of interest that could be perceived as prejudicing the impartiality of this research.

\section{Originality}

The authors confirm that this manuscript is their original work and has not been previously published nor is sent to another journal for consideration.

Funding

The authors declare that there was no financial support and sponsorship for this research and its publication and that it did not receive any specific grant from funding agencies in the public, commercial, or notfor-profit sectors.

\section{Authors' contributions}

Naida Omerović: concept/design, data collection, data analysis/interpretation, drafting the manuscript, critical revision of the manuscript, approval of the manuscript; Edina Vranić: concept/design, data analysis/interpretation, critical revision of the manuscript, approval of the manuscript.

\section{Consent}

Not applicable.

Ethical approval

Not applicable.

\section{References Références Referencias}

1. Lee VH, Robinson JR. Topical ocular drug delivery: recent developments and future challenges. J Ocul Pharmacol. 1986; 2(1): 67-108. PMID: 3332284, doi: 10.1089/jop.1986.2.67.

2. Runkle EA, Antonetti DA. The blood-retinal barrier: structure and functional significance. Methods Mol Biol. 2011; 686(1): 133-48. PMID: 21082369, doi: 10.1007/978-1-60761-938-3 5.

3. Omerović N, Vranić E. Application of nanoparticles in ocular drug delivery systems. Health Technol. 2020; 10(1): 61-78. doi: 10.1007/s12553-01900381-w.

4. Urtti A. Challenges and obstacles of ocular pharmacokinetics and drug delivery. Adv Drug Deliv Rev. 2006; 58(11): 1131-5. PMID: 17097758, doi: 10.1016/j.addr.2006.07.027.
5. Patel A, Cholkar K, Agrahari V, Mitra AK. Ocular drug delivery systems: an overview. World J Pharmacol. 2013; 2(2): 47-64. PMID: 25590022, PMCID: PMC4289909, doi: 10.5497/wjp.v2.i2.47.

6. Baranowski P, Karolewicz B, Gajda M, Pluta J. Ophthalmic drug dosage forms: characterisation and research methods. Scientific World Journal. 2014; 2014: 861904. PMID: 24772038, PMCID: PMC3977496, doi: 10.1155/2014/861904.

7. Reimondez-Troitiño S, Csaba N, Alonso MJ, De La Fuente M. Nanotherapies for the treatment of ocular diseases. Eur J Pharm Biopharm. 2015; 95(PtB): 279-93. PMID: 25725262, doi: 10.1016/j.ejpb. 2015.02.019.

8. Cholkar K, Patel A, Vadlapudi DA, Mitra AK. Novel nanomicellar formulation approaches for anterior and posterior segment ocular drug delivery. Recent Pat Nanomed. 2012; 2(2): 82-95. PMID: 25400717, PMCID: PMC4232191, doi: 10.2174/1877912311 202020082.

9. Paolicelli P, Prego C, Sánchez A, Alonso MJ. Surface-modified PLGA-based nanoparticles that can efficiently associate and deliver virus-like particles. Nanomedicine (Lond). 2010; 5(6): 843-53. PMID: 20735221, doi: 10.2217/nnm.10.69.

10. Kondiah $\mathrm{P}$, Choonara $\mathrm{Y}$, Kondiah $\mathrm{P}$, Marimuthu $\mathrm{T}$, Kumar $P$, du Toit L, et al. Nanocomposites for therapeutic application in multiple sclerosis. In: Inamuddin, Asiri AM, Mohammad A, editors. Applications of nanocomposite materials in drug delivery. 1st ed. Amsterdam: Elsevier; 2018. p. 391-408.

11. Muhamad I, Selvakumaran S, Lazim N. Designing polymeric nanoparticles for targeted drug delivery system. In: Seifalian A, De Mel A, Kalaskar DM, editors. Nanomedicine. 1st ed. Manchester: One Central Press; 2014. p. 287-313.

12. Müller $R H$, Radtke $M$, Wissing $S A$. Solid lipid nanoparticles (SLN) and nanostructured lipid carriers (NLC) in cosmetic and dermatological preparations. Adv Drug Deliv Rev. 2002; 54(1): S131-55. PMID: 12460720, doi: 10.1016/s0169409x(02)00118-7.

13. Üner M, Yener G. Importance of solid lipid nanoparticles (SLN) in various administration routes and future perspectives. Int $\mathrm{J}$ Nanomedicine. 2007; 2(3): 289-300. PMID: 18019829, PMCID: PMC2 676658.

14. Hirlekar R, Garse H, Kadam V. Solid lipid nanoparticles and nanostructured lipid carriers: a review. Curr Drug Ther. 2011; 6(4): 240-50. doi: 10.2174/157488511798109637.

15. Gaudana R, Ananthula HK, Parenky A, Mitra AK. Ocular drug delivery. AAPS J. 2010; 12(3): 348-60. PMID: 20437123, PMCID: PMC2895432, doi: 10.1208/s12248-010-9183-3. 
16. Amrite AC, Kompella UB. Size-dependent disposition of nanoparticles and microparticles following subconjunctival administration. J Pharm Pharmacol. 2005; 57(12): 1555-63. PMID: 16354399, doi: 10.1211/jpp.57.12.0005.

17. Amrite AC, Edelhauser HF, Singh SR, Kompella UB. Effect of circulation on the disposition and ocular tissue distribution of $20 \mathrm{~nm}$ nanoparticles after periocular administration. Mol Vis. 2008; 14(1): 15060. PMID: 18334929, PMCID: PMC2254958.

18. Cheruvu NP, Amrite AC, Kompella UB. Effect of eye pigmentation on transscleral drug delivery. Invest Ophthalmol Vis Sci. 2008; 49(1): 333-41. PMID: 18172110, PMCID: PMC3324932, doi: 10.1167/ iovs.07-0214.

19. Cheruvu NP, Amrite AC, Kompella UB. Effect of diabetes on transscleral delivery of celecoxib. Pharm Res. 2009; 26(2): 404-14. PMID: 18987961, doi: 10.1007/s11095-008-9757-2.

20. Kompella UB, Sundaram S, Raghava S, Escobar ER. Luteinizing hormone-releasing hormone agonist and transferrin functionalizations enhance nanoparticle delivery in a novel bovine ex vivo eye model. Mol Vis. 2006; 12(1): 1185-98. PMID: 17102798.

21. Eljarrat-Binstock E, Orucov F, Aldouby Y, FruchtPery J, Domb AJ. Charged nanoparticles delivery to the eye using hydrogel iontophoresis. J Control Release. 2008; 126(2): 156-61. PMID: 18201790, doi: 10.1016/j.jconrel.2007.11.016.

22. Kim H, Robinson SB, Csaky KG. Investigating the movement of intravitreal human serum albumin nanoparticles in the vitreous and retina. Pharm Res. 2009; 26(2): 329-37. PMID: 18958405, doi: 10.1007/s11095-008-9745-6.

23. Agrahari $V$, Mandal $A$, Agrahari $V$, Trinh HM, Joseph $M$, Ray A, et al. A comprehensive insight on ocular pharmacokinetics. Drug Deliv Transl Res. 2016; 6(6): 735-54. PMID: 27798766, PMCID: PMC5319401, doi: 10.1007/s13346-016-0339-2.

24. Mudgil M, Gupta N, Nagpal M, Pawar P. Nanotechnology: a new approach for ocular drug delivery system. Int J Pharm Pharm Sci. 2012; 4(2): 105-12. Available: https://www.researchgate. net/profile/Manju-Nagpal/publication/272495532 Nanotechnology_A_new_approach_for_ocular_drug _delivery_system/links/54e6dc8b0cfocō2e0290̄b0ee /Nanotechnology-A-new-approach-for-ocular-drugdelivery-system.pdf.

25. Pinto Reis C, Neufeld RJ, Ribeiro AJ, Veiga F. Nanoencapsulation I. Methods for preparation of drug-loaded polymeric nanoparticles. Nanomedicine. 2006; 2(1): 8-21. PMID: 17292111, doi: 10.1016/j.nano.2005.12.003.

26. Fan Q, Mani G. Dyeable polypropylene via nanotechnology. In: Brown P, Stevens K, editors.
Nanofibers and nanotechnology in textiles. 1st ed. Sawston: Woodhead Publishing; 2007. p. 320-50.

27. Thote AJ, Gupta RB. Formation of nanoparticles of a hydrophilic drug using supercritical carbon dioxide and microencapsulation for sustain release. Nanomedicine. 2005; 1(1): 85-90. PMID: 17292062, doi: 10.1016/j.nano.2004.12.001.

28. Chattopadhyay P, Gupta RB. Production of griseofulvin nanoparticles using supercritical $\mathrm{CO}(2)$ antisolvent with enhanced mass transfer. Int $\mathrm{J}$ Pharm. 2001; 228(1-2): 19-31. PMID: 11576765, doi: 10.1016/s0378-5173(01)00803-1.

29. Reverchon E, Adami R. Nanomaterials and supercritical fluids. J Supercrit Fluids. 2006; 37(1): 1-22. doi: 10.1016/j.supflu.2005.08.003.

30. Cabanas A, Poliakoff M. The continuous hydrothermal synthesis of nano-particulate ferrites in near critical and supercritical water. J Mater Chem. 2001; 11(5): 1408-16. doi: 10.1039/b009428p.

31. Cansell F, Aymonnier C. Design of functional nanostructured materials using supercritical fluids. J Supercrit Fluids. 2009; 47(3): 508-16. doi: 10.1016/j.supflu.2008.10.002.

32. Wu K, Li J, Wang W, Winstead DA. Formation and characterization of solid dispersions of piroxicam and polyvinylpyrrolidone using spray drying and precipitation with compressed antisolvent. J Pharm Sci. 2009; 98(7): 2422-31. PMID: 18972575, doi: 10.1002/jps.21598.

33. Reverchon E, Della Porta G, Di Trolio A, Pace S. Supercritical antisolvent precipitation of nanoparticles of superconductor precursors. Ind Eng Chem Res. 1998; 37(3): 952-8. doi: 10.1021/ie970510a.

34. Subramaniam B, Rajewski RA, Snavely K. Pharmaceutical processing with supercritical carbon dioxide. J Pharm Sci. 1997; 86(8): 885-90. PMID: 9269864, doi: 10.1021/js9700661.

35. Rantakylä $M$, Jäntti $M$, Aaltonen $O$, Hurme $M$. The effect of initial drop size on particle size in the supercritical antisolvent precipitation (SAS) technique. J Supercrit Fluids. 2002; 24(3): 251-63. doi: 10.1016/S0896-8446(02)00034-7.

36. Sellers SP, Clark GS, Sievers RE, Carpenter JF. Dry powders of stable protein formulations from aqueous solutions prepared using supercritical CO2-assisted aerosolization. J Pharm Sci. 2001; 90(6): 785-97. PMID: 11357179, doi: 10.1002/ jps. 1032 .

37. Sievers RE, Huang ETS, Villa JA, Engling G, Brauer PR. Micronization of water-soluble or alcoholsoluble pharmaceuticals and model compounds with a low-temperature Bubble Dryer (R). J Supercrit Fluids. 2003; 26(1): 9-16. doi: 10.1016/S08968446(02)00188-2. 
38. Reverchon E, Della Porta G. Particle design using supercritical fluids. Chem Eng Tech. 2003; 26(8): 840-5. doi: 10.1002/ceat.200300005.

39. Reverchon E, Della Porta G. Micronization of antibiotics by supercritical assisted atomization. J Supercritic Fluids. 2003; 26(3): 243-52. doi: 10.1016/ S0896-8446(02)00162-6.

40. Vemavarapu C, Mollan MJ, Lodaya M, Needham TE. Design and process aspects of laboratory scale SCF particle formation systems. Int J Pharm. 2005; 292(1-2): 1-16. PMID: 15725549, doi: 10.1016/ j.ijpharm.2004.07.021.

41. Teja AS, Eckert CA. Commentary on supercritical fluids: research and applications. Ind Eng Chem Res. 2000; 39(12): 4442-4. doi: 10.1021/ie000 915m.

42. Blasig A, Shi CM, Enick RM, Thies MC. Effect of concentration and degree of saturation on RESS of a CO2-soluble fluoropolymer. Ind Eng Chem Res. 2002; 41(20): 4976-83. doi: 10.1021/ie0201819.

43. Yeo SD, Kiran E. Formation of polymer particles with supercritical fluids: a review. J Supercrit Fluids. 2005; 34(3): 287-308. doi: 10.1016/j.supflu.2004. 10.006.

44. Meziani MJ, Pathak P, Sun YP. Supercritical fluid technology for nanotechnology in drug delivery. In: De Villiers MM, Aramwit P, Kwon GS, editors. Nanotechnology in drug delivery. 1st ed. New York: Springer-Verlag; 2009. p. 69-104.

45. Jung J, Perrut MJ. Particle design using supercritical fluids: literature and patent survey. J Supercrit Fluids. 2001; 20(3):179-219. doi: 10.1016/S08968446(01)00064-X.

46. Sheth $P$, Sandhu $H$, Singhal D, Malick W, Shah N, Serpil Kislalioglu M. Nanoparticles in the pharmaceutical industry and the use of supercritical fluid technologies for nanoparticle production. Curr Drug Deliv. 2012; 9(3): 269-84. PMID: 22283656, doi: $10.2174 / 156720112800389052$.

47. Helfgen B, Turk M, Schaber K. Theoretical and experimental investigations of the micronization of organic solids by rapid expansion of supercritical solutions. Powder Technol. 2000; 110(1-2): 22-8. doi: 10.1016/S0032-5910(99)00264-8.

48. Weber M, Thies MC. Understanding the RESS process. In: Sun YP, editor. Supercritical fluid technology in materials science and engineering: synthesis properties and applications. 1st ed. New York: Marcel Dekker; 2002. p. 385-439.

49. Thakur R, Gupta RB. Rapid expansion of supercritical solution with solid cosolvent (RESS-SC) process: formation of griseofulvin nanoparticles. Ind Eng Chem Res. 2005; 44(19): 7380-7. doi: 10.1021/ie050417j.

50. Thakur R, Gupta RB. Rapid expansion of supercritical solution with solid cosolvent (RESS-SC) process: formation of 2-aminobenzoic acid nanoparticle. J Supercrit Fluids. 2006; 37(3): 30715. doi: 10.1016/j.supflu.2005.12.008.

51. Thakur R, Gupta RB. Formation of phenytoin nanoparticles using rapid expansion of supercritical solution with solid cosolvent (RESS-SC) process. Int J Pharm Sci. 2006; 308(1-2): 190-9. PMID: 16352406, doi: 10.1016/j.jpharm.2005.11.005.

52. Young TJ, Mawson S, Johnston KP, Henriksen IB, Pace GW, Mishra AK. Rapid expansion from supercritical to aqueous solution to produce submicron suspensions of water-insoluble drugs. Biotechol Prog. 2000; 16(3): 402-7. PMID: 10835242, doi: 10.1021/bp000032q.

53. Hu J, Johnston KP, Williams III RO. Nanoparticle engineering processes for enhancing the dissolution rates of poorly water soluble drugs. Drug Dev Ind Pharm. 2004; 30(3): 233-45. PMID: 15109023, doi: 10.1081/ddc-120030422.

54. Chen XX, Young TJ, Sarkari M, Williams RO, Johnston KP. Preparation of cyclosporine A nanoparticles by evaporative precipitation into aqueous solution. Int J Pharm. 2002; 242(1-2): 314. PMID: 12176220 , doi: 10.1016/s0378-5173(02) 00147-3.

55. Kwauk X, Debenedetti PG. Mathematical modeling of aerosol formation by rapid expansion of supercritical solutions in a converging nozzle. J Aerosol Sci. 1993; 24(4): 445-69.

56. Reverchon E, Pallaso P. Hydrodynamic modeling of the RESS process. J Supercrit Fluids. 1996; 9(4): 216-21.

57. Hirunsit P, Huang $Z$, Srinophakun T, Charoenchaitrakool M, Kawi S. Particle formation of ibuprofen-supercritical $\mathrm{CO} 2$ system from rapid expansion of supercritical solutions (RESS): a mathematical model. Powder Technol. 2005; 154 (2-3): 83-94. doi: 10.1016/j.powtec.2005.03.020.

58. Türk M. Influence of thermodynamic behavior and solute properties on homogeneous nucleation in supercritical solutions. J Supercrit Fluids. 2000; 18(3): 169-84. doi: 10.1016/S0896-8446(00)000802.

59. Helfgen B, Hils P, Holzknecht C, Türk M, Schaber K. Simulation of particle formation during the rapid expansion of supercritical solutions. J Aerosol Sci. 2001; 32(3): 295-319. doi: 10.1016/S0021-8502 (00)00080-X.

60. Weber M, Russell LM, Debenedetti PG. Mathematical modeling of nucleation and growth of particles formed by the rapid expansion of a supercritical solution under subsonic conditions. J Supercrit Fluids. 2002; 23(1): 65-80. doi: 10.1016/S0896-8446(01)00134-6.

61. Lengsfeld CS, Delplanque JP, Barocas VH, Randolph TW. Mechanism governing microparticle morphology during precipitation by a compressed antisolvent: atomization vs nucleation and growth. J 
Phys Chem B. 2000; 104(12): 2725-35. doi: 10.1021/jp9931511.

62. Werling JO, Debenedetti PG. Numerical modeling of mass transfer in the supercritical antisolvent process: miscible conditions. J Supercrit Fluids. 2000; 18(1): 11-24. doi: 10.1016/S0896-8446(00) 00054-1.

63. Reverchon E, Adami R, Caputo G, De Marco I. Spherical microparticles production by supercritical antisolvent precipitation: interpretation of results. J Supercrit Fluids. 2008; 47(1): 70-84. doi: 10.1016/ j.supflu.2008.06.002.

64. Braeuer A, Dowy S, Torino E, Rossmann M, Luther SK, Schluecker E, et al. Analysis of the supercritical antisolvent mechanisms governing particles precipitation and morphology by in situ laser scattering techniques. Chem Eng J. 2011; 173(1): 258-66. doi: 10.1016/j.cej.2011.07.064.

Abbreviations

BRB - blood-retinal barrier

CAN-BD - CO2-assisted nebulisation with a bubble dryer

HSA - human serum albumin

$\mathrm{LHRH}$ - luteinizing hormone-releasing hormone

NLC - nanostructured lipid carriers

PEG - poly(ethylene glycol)

PS - polystyrene

RESAS - rapid expansion from supercritical to aqueous solution

RESS - rapid expansion of the supercritical solution

RESS-SC - rapid expansion of the supercritical solution with solid co-solvent

RPE - retinal pigment epithelium

SAA - supercritical fluid-assisted atomisation

SAS - supercritical anti-solvent

SLN - solid lipid nanoparticles

w/o - water/oil 